\title{
Detonation Product EOS Studies: Using ISLS to Refine Cheetah
}

\author{
J. M. Zaug, W. M. Howard, L. E. Fried, D. W. Hansen
}

This article was submitted to $12^{\text {th }}$ American Physical Society Topical Conference, Atlanta, GA., June 24-29, 2001

\section{August 8, 2001}

U.S. Department of Energy

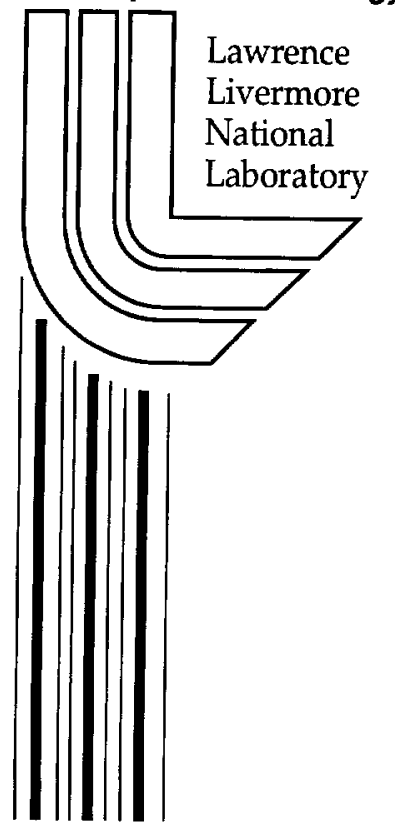

Approved for public release; further dissemination unlimited 


\section{DISCLAIMER}

This document was prepared as an account of work sponsored by an agency of the United States Government. Neither the United States Government nor the University of California nor any of their employees, makes any warranty, express or implied, or assumes any legal liability or responsibility for the accuracy, completeness, or usefulness of any information, apparatus, product, or process disclosed, or represents that its use would not infringe privately owned rights. Reference herein to any specific commercial product, process, or service by trade name, trademark, manufacturer, or otherwise, does not necessarily constitute or imply its endorsement, recommendation, or favoring by the United States Government or the University of California. The views and opinions of authors expressed herein do not necessarily state or reflect those of the United States Government or the University of California, and shall not be used for advertising or product endorsement purposes.

This is a preprint of a paper intended for publication in a journal or proceedings. Since changes may be made before publication, this preprint is made available with the understanding that it will not be cited or reproduced without the permission of the author.

This work was performed under the auspices of the United States Department of Energy by the University of California, Lawrence Livermore National Laboratory under contract No. W-7405-Eng-48.

This report has been reproduced directly from the best available copy.

Available electronically at http://www.doc.gov/bridge

Available for a processing fee to U.S. Department of Energy

And its contractors in paper from

U.S. Department of Energy

Office of Scientific and Technical Information

P.O. Box 62

Oak Ridge, TN 37831-0062

Telephone: (865) 576-8401

Facsimile: (865) 576-5728

E-mail: reports@adonis.osti.gov

Available for the sale to the public from

U.S. Department of Commerce

National Technical Information Service

5285 Port Royal Road

Springfield, VA 22161

Telephone: (800) 553-6847

Facsimile: (703) 605-6900

E-mail: orders@ntis.fedworld.gov

Online ordering: http://www.ntis.gov/ordering.htm

OR

Lawrence Livermore National Laboratory

Technical Information Department's Digital Library

http://www.llnl.gov/tid/Library.html 


\title{
Detonation Product EOS Studies: Using ISLS to Refine Cheetah ${ }^{*}$
}

\author{
J. M. Zaug, W. M. Howard, L. E. Fried, and D. W. Hansen \\ University of California, Lawrence Livermore National Laboratory. \\ 7000 East Ave., Livermore, CA 94550
}

\begin{abstract}
Knowledge of an effective interatomic potential function underlies any effort to predict or rationalize the properties of solids and liquids. The experiments we undertake are directed towards determination of equilibrium and dynamic properties of simple fluids at densities sufficiently high that traditional computational methods and semi-empirical forms successful at ambient conditions may require reconsideration.

In this paper we present high-pressure and temperature experimental sound speed data on a simple fluid, methanol. Impulsive Stimulated Light Scattering (ISLS) conducted on diamond-anvil cell (DAC) encapsulated samples offers an experimental approach to determine cross-pair potential interactions through equation of state determinations. In addition the kinetics of structural relaxation in fluids can be studied. We compare our experimental results with our thermochemical computational model Cheetah. Computational models are systematically improved with each addition of experimental data. Experimentally grounded computational models provide a good basis to confidently understand the chemical nature of reactions at extreme conditions.
\end{abstract}

\section{INTRODUCTION}

Experiments at extreme conditions of pressure and/or temperature provide insight into a realm of chemical and material properties that are significantly different from those encountered under ambient conditions. Such studies extend and test the theoretical framework which permits progress from properties at the atomic and molecular level to macroscopic behavior, constitute a potential source of novel materials and new tools for chemical transformation and are important adjuncts to progress in other disciplines. There is no question that an improved general knowledge of electronic, physical, and chemical behavior of relevant constituent materials at high density is required, for example, for a less fragmented description of the processes that precede and direct exothermic chemical reactions. The purpose of the work described in this paper is to ultimately develop a science based hydrodynamic tool that allows us to confidently predict material properties and states under chemically and physically extreme conditions not currently achievable in the laboratory setting.
Dynamical simulation based on approximate Born-Oppenheimer potentials plays a large and increasingly important role in chemistry and in the biological and materials sciences. More generally, knowledge of an effective interatomic potential function underlies any effort to predict or rationalize the properties of solids and liquids. Particularly in systems associated with experimentally difficult temperatures or pressures, such as prevail in the deep interiors of the Earth and giant planets, dynamical simulation based on computed potentials seems at present the most promising predictive resource. While there exists an extensive body of experimental techniques and experience on computational methods appropriate to ambient conditions, the regime of strong repulsive interactions at very high densities has not been as extensively investigated The experiments discussed here are aimed both at enlarging the family of properties conveniently measured at high pressure and, principally, at providing the data appropriate to a critical test of the theory of the internuclear potential in simple substances at high density. 


\section{EXPERIMENTAL}

The optical technique Impulsive Stimulated Light Scattering (ISLS) is discussed in general in Refs [1-2] and specifically in the context of the DAC in Refs. [3-5]. Briefly, two successive "excitation" pulses, $(30 \mu), 60 \mu \mathrm{m}$ diameter, -100 ps duration) are selected from the output train of a Q-switched $(500 \mathrm{~Hz})$, mode-locked Nd:YAG laser and recombined in the sample at an angle 20 , but otherwise coincident in space and time. Interference establishes a periodic distribution of intensity and, in a sample that absorbs in the near infrared, a (spatially) periodic variation in the temperature and pressure ensues. The coupling between laser light and the excited material modes is such that the local temperature rise remains "impulsive." The associated thermal pressure launches counterpropagating acoustic waves. The acoustic wavelength, $d$, in this case equal to the period of the optical grating, may be expressed in terms of the excitation wavelength, $\lambda_{E}=1.064 \mu \mathrm{m}$, and $\theta$ as

$$
d=\lambda_{A}=\frac{\lambda_{E}}{2 \sin \theta}
$$

In a fluid sample one longitudinal wave is excited The impulsively excited acoustic wave induces a temporally and spatially periodic variation in the index of refraction of the sample. A third pulse $(\sim 1$ $\mu \mathrm{J}, 20 \mu \mathrm{m}$ diameter, -80 ps duration) selected from the same Q-switched envelope as the excitation pulses is frequency doubled $\left(\lambda_{p}=0.532 \mu \mathrm{m}\right)$ and delayed by a combination of time of flight and mode lock pulse selection to generate the "probe." Observation of the intensity of the Bragg scattering of the probe, by the acoustic or thermoacoustic grating, as a function of probe delay serves to determine the frequency $(v)$, and hence the adiabatic velocity $(c=d v)$ of the acoustic waves.

In practice, grating spacings are determined by making the same measurement on a piece of glass with a known speed of sound and which gives a strong, stable signal suitable for a calibrant. The glass was in turn calibrated against water and fused silica [6-8]. The velocity is typically determined with a precision of $< \pm 0.2 \%$.

Pressure determinations were made by monitoring the wavelength of the fluorescence (excited by a $\mathrm{He}-\mathrm{Cd}$ laser or by the $488-\mathrm{nm} \mathrm{Ar}^{+}$laser line) of ruby chips which surround or are embedded in the sample. Rubies after grinding to tens of microns have residual strains which are often large enough to offset pressure measurements by $-0.05 \mathrm{GPa}$, and occasionally as much as $0.2 \mathrm{GPa}$. Annealing at $\sim 1000^{\circ} \mathrm{C}$ for several hours decreases both the magnitude and frequency of these deviations yet it is still common to find rubies which differ reproducibly by the equivalent of $0.02 \mathrm{GPa}$. The most precise work completed has been on the melting curve of $\mathrm{O}_{2}$, in which the relative wavelengths of rubies were recorded at $0 \mathrm{GPa}$ and the high-pressure results corrected by the same amounts. The reference rubies at $0 \mathrm{GPa}$ were kept in the same temperature controlled housing as were the samples, because wavelength shifts equivalent to $0.01 \mathrm{GPa}$ are generated by temperature differences of $0.5^{\circ} \mathrm{C}$ and in order to match as closely as possible the two spectral line shapes. With hydrostatic samples one can measure pressures with a precision of slightly better than $0.01 \mathrm{GPa}$. A $1 / 4 \mathrm{~m}$ spectrometer . (1200 grooves $/ \mathrm{mm}$ grating) and 750 bin CCD $(11 \mu \mathrm{m}$ pixel width) gave a dispersion of $2.3 \times 10^{-3} \AA / \mathrm{bin}$. Micro FTIR spectra were taken on a Bruker Optics vector-33 FTIR spectrometer ( $4 \mathrm{~cm}^{-1}$ resolution).

\section{COMPUTATIONAL}

Cheetah is a thermochemical code that is used to predict detonation performance for solid and liquid explosives. Cheetah solves thermodynamic equations between product species to find chemical equilibrium for a given pressure and temperature. Chapman-Jouget (C-J) theory says that the detonation point is a state in thermodynamic and chemical equilibrium, so Cheetah can predict the properties of this state. From these properties and elementary detonation theory the detonation velocity and other performance indicators are computed.

Thermodynamic equilibrium is found by balancing chemical potentials, where the chemical potentials of condensed species are just functions of pressure and temperature, while the potentials of gaseous species also depend on concentrations. In order to solve for the chemical potentials, it is necessary to know the pressure-volume relations for species that are important products in detonation. Moreover, it is necessary to know these relations at the high pressures and temperatures that typically characterize the CI 
state. Thus, there is a need for improved highpressure equations of state for fluids, particularly for molecular fluid mixtures. The exponential- 6 (exp-6) potential model defines the energy of interaction of a classical fluid composed of identical spherical particles. This model has been used with considerable success to describe the equation of state of many materials over a wide range of pressure and temperature [9].

The exp-6 potential has also proved successful in modeling chemical equilibrium at the high pressures and temperatures characteristic of detonation. However, in order to calibrate the parameters for such models, it is necessary to have experimental data for molecules and mixtures of molecular species at high temperature and pressure. Static compression data, as well as sound speed measurements, provide important data for these models.

\section{RESULTS AND DISCUSSION}

The sound velocity of pure methanol $(\mathrm{MeOH})$ was measured along a $250^{\circ} \mathrm{C}$ isotherm up to 3.9 $\mathrm{GPa}$. A comparison of ISLS experimental data and Cheetah computational results is given in figure 1 . The $-3 \%$ difference between data sets shows the utility of Cheetah and likewise the potential for further refinement of the exp- 6 potential. After each data point was taken the sample was cooled and the velocity was again measured and compared to previous measurements of uncooked $\mathrm{MeOH}[10]$. No appreciable velocity difference between data sets was observed. An attempt was then made to measure the velocity of $\mathrm{MeOH}$ at $5 \mathrm{GPa}$, but at this pressure $\mathrm{MeOH}$ froze. The sample was then brought up to $325^{\circ} \mathrm{C}$ where it promptly began to phase separate into supercritical reaction products figure 2. Upon cooling, brownish platelet looking forms were observed at $315^{\circ} \mathrm{C}$. Heat was again applied, and the formation of carbon tendrils began at $331^{\circ} \mathrm{C}$. These carbon tendrils retreated at $325^{\circ} \mathrm{C}$. Upon cooling brown platelets re-appeared at $316^{\circ}$. At this point the furnace was removed from the optical table and placed on a microscope stage where digital micro-graphs were taken of the bubbles as they dissipated and eventually froze, figure 3. Some of the smaller bubbles contained diamond. We compared FTIR spectra of the frozen sample to $\mathrm{MeOH}$ at ambient conditions, fig. 4 .

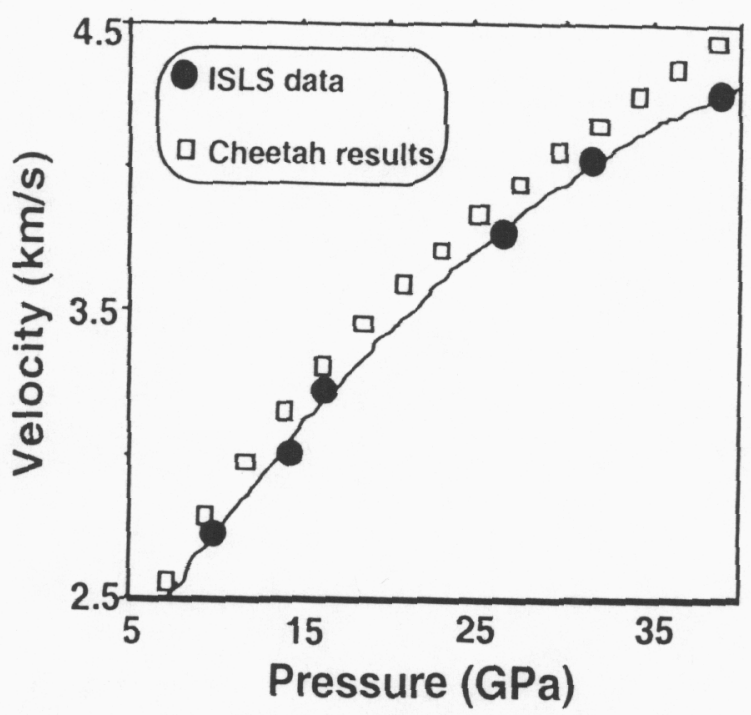

Figure 1: ISLS and Cheetah results for the $\mathrm{MeOH}$ at $250^{\circ} \mathrm{C}$.

In addition FTIR spectra was taken of previously cooked $\mathrm{MeOH}\left(300^{\circ} \mathrm{C}\right)$ at $2.2 \mathrm{GPa}$ and $24^{\circ} \mathrm{C}$. The line assignments for ambient $\mathrm{MeOH}$ peaks $\mathrm{A}$ and $\mathrm{B}$ are $\mathrm{C}-\mathrm{O}$ stretch and $\mathrm{O}-\mathrm{H}$ bending + symmetrical $\mathrm{CH}_{3}$ bending respectively. The $\mathrm{C}$ peaks are $\mathrm{C}-\mathrm{H}$

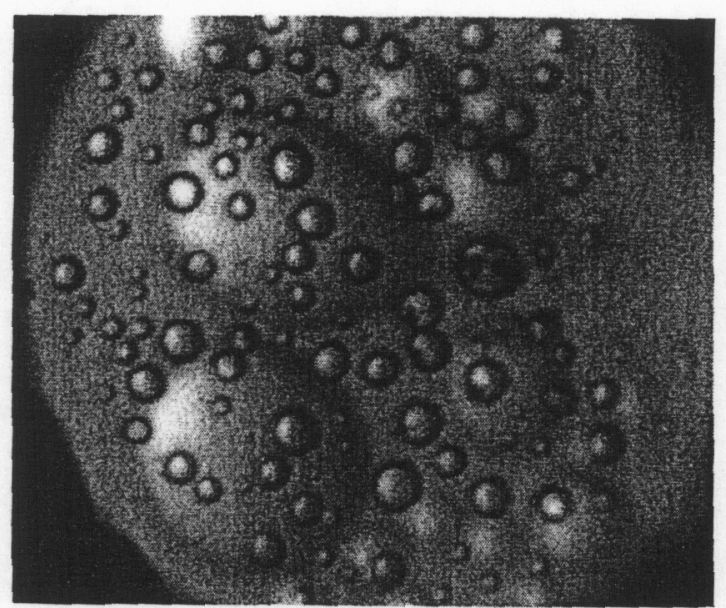

Figure 2: $\mathrm{MeOH}$ product bubbles at $250^{\circ} \mathrm{C}$ and $5 \mathrm{GPa}$.

stretching modes and peak $\mathrm{D}$ is $\mathrm{O}-\mathrm{H}$ stretching with an intermolecular hydrogen bonded network. High-pressure FTIR spectra indicates that pressure completely attenuates bending mode frequencies. The intensity of peak $\mathrm{B}$ (reacted $\mathrm{MeOH}$ spectra) increased with heat soak time above $300^{\circ} \mathrm{C}$ and may indicate the presence of a simple carbonyl, 


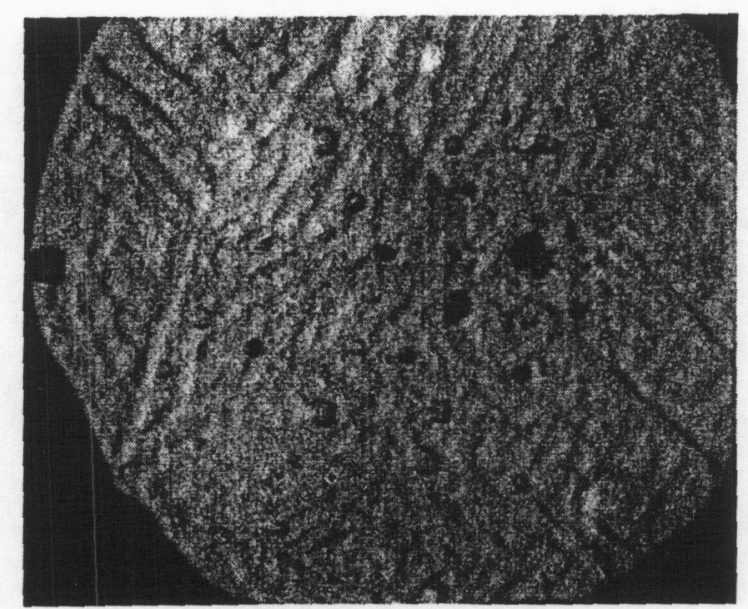

Figure 3: $\mathrm{MeOH}$ products frozen at $25^{\circ} \mathrm{C}$. A spot seen at 9 $0^{\prime}$ clock is ruby used to optically measure pressure.

perhaps formaldehyde. Peak $\mathrm{C}$ is blue shifted $\mathrm{C}-\mathrm{H}$ stretching modes and peak $\mathrm{D}$ is again $\mathrm{O}-\mathrm{H}$ stretch where now there is no $\mathrm{H}-\mathrm{H}$ exchange occurring.

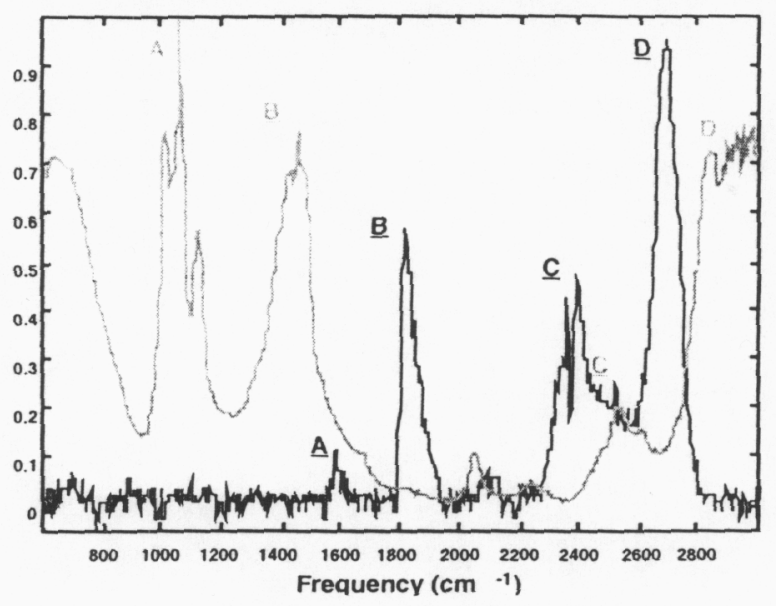

Figure 4: micro-FTIR spectra of pure $\mathrm{MeOH}$ at ambient conditions (gray line) and reacted $\mathrm{MeOH}$ cooled to room temperature with frozen constituents at $5 \mathrm{GPa}$ (dark line).

\section{CONCLUSIONS}

We have measured the sound speed of supercritical $\mathrm{MeOH}$ at $250^{\circ} \mathrm{C}$ up to $3.9 \mathrm{GPa}$. $\mathrm{MeOH}$ froze at $5 \mathrm{GPa}$. An attempt to carry on the sound speed study along a $325^{\circ} \mathrm{C}$ isotherm was thwarted by chemical reaction toward products that may include water, ethane, methane, diamond, and perhaps formaldehyde. We will have the capability to run FTIR and sound velocity measurements simultaneously in the near future.

\section{ACKNOWLEDGEMENTS}

The authors thank Dr. S. Wang, Bruker Optics, for collecting $\mu$-FTIR spectra.

* This work performed under the auspices of the U.S. Department of Energy by the Lawrence Livermore National Laboratory under contract number W-7405-Eng-48.

\section{REFERENCES}

[1] Yan, Y. X., Cheng L. T., and Nelson K A. "Impulsive Stimulated Scattering," in Advances in Non-linear Spectroscopy, J. H. Clark and R. E. Hester, Eds. John Wiley Ltd. London, (1987).

[2] Fayer, M. D., IEEE J. Quantum Electronics, 22, p. 1444, (1986)

[3] Brown, J. M., Slutsky L. J., Nelson K. A., and Cheng L. T., "Velocity of Sound and Equation of State of Methanol and Ethanol in a Diamond Anvil Cell: An Application of Impulsive Stimulated Scattering," Science, 241, p. 65, (1988).

[4] Zaug, J. M., Abramson, E. H., Brown, J. M. and Slutsky, L. J., "Elastic Constants, Equations of State and Thermal Diffusivity at High Pressure" in High Pressure Research; Applications to Earth and Planetary Sciences, Y. Syono and M. Manghnani Eds., 157-166, American Geophysical Union, Washington D. C., (1992).

[5] Zaug, J. M., Ph.D. Thesis, (University of Washington, Seattle, December 1994).

[6] Greenspan, M., and Tschiegg, C. E., J. Acoust. Soc. Am., 31, 75-76, (1959).

[7] Wilson W. D, J. Acoust. Soc. Am., 31, 1067-1072, (1959).

[8] American Institute of Physics Handbook (McGraw-Hill, New York, 1957).

[9] Fried, L. E., and Howard, W. M., J. Chem. Phys. 109 (17): 7338-7348 (1998).

[10] Zaug J. M., Brown J. M., and Slutsky L. J., J. Phys. Chem., 98, 6008-6016, (1994). 